\title{
The ontogeny of learned inhibition
}

\author{
Heidi C. Meyer ${ }^{1}$ and David J. Bucci ${ }^{1,2}$ \\ ${ }^{1}$ Department of Psychological and Brain Sciences, Dartmouth College, Hanover, New Hampshire 03755, USA
}

\begin{abstract}
Previous studies have examined the maturation of learning and memory abilities during early stages of development. By comparison, much less is known about the ontogeny of learning and memory during later stages of development, including adolescence. In Experiment 1, we tested the ability of adolescent and adult rats to learn a Pavlovian negative occasion setting task. This procedure involves learning to inhibit a behavioral response when signaled by a cue in the environment. During reinforced trials, a target stimulus (a tone) was presented and immediately followed by a food reward. On nonreinforced trials, a feature stimulus (a light) was presented $5 \mathrm{sec}$ prior to the tone and indicated the absence of reward following presentation of the tone. Both adult and adolescent rats learned to discriminate between two different trial types and withhold responding when the light preceded the tone. However, adolescent rats required more sessions than adults to discriminate between reinforced and nonreinforced trials. The results of Experiment 2 revealed that adolescents could learn the task rules but were specifically impaired in expressing that learning in the form of withholding behavior on nonreinforced trials. In Experiment 3, we found that adolescents were also impaired in learning a different version of the task in which the light and tone were presented simultaneously during the nonreinforced trials. These findings add to existing literature by indicating that impairments in inhibitory behavior during adolescence do not reflect an inability to learn to inhibit a response, but instead reflect a specific deficit in expressing that learning.
\end{abstract}

Substantial prior research has examined the maturation of learning and memory abilities during early stages of development. For example, cerebellar delay eye blink conditioning is known to emerge in rats between postnatal days (PND) 17-24 (Stanton et al. 1992; Ivkovich et al. 2000), hippocampal memory between PNDs 18-23 (Rudy and Morledge 1994), and learned fear responses to odor conditioned stimuli as early as PND 12 (Hunt et al. 1998). By comparison, much less is known about the ontogeny of learning and memory during later stages of development, including adolescence. Adolescence is characterized by numerous nonlinear changes in behavior and brain development, underscoring the importance of studying this developmental period. Indeed, compared to either early preadolescence or adulthood, adolescence is marked by both increases and decreases in function on various physical, psychological, and social measures (Galvan et al. 2006; Somerville et al. 2011; Naneix et al. 2012; Sturman and Moghaddam 2012; Somerville 2013). For example, it has recently been shown that adolescent mice exhibit a specific and transient amnesia for contextual fear memory compared to either adult or preadolescent mice (Pattwell et al. 2011, 2012, 2013). Studies such as these are integral to establishing the basis for common neurocognitive disorders that emerge during adolescence, including attention-deficit hyperactivity-disorder (ADHD), schizophrenia, and drug addiction.

It is well documented that various aspects of inhibitory behavior are attenuated during adolescence in both humans and laboratory rats (Liston et al. 2006; Casey et al. 2008; Hare et al. 2008; Andrzejewski et al. 2011; Sun et al. 2012). Indeed, although the ability to control behavior is evident earlier in development (Johnson 1995), adolescents often forgo appropriate behaviors in the face of reward, leading to heightened risk-taking and impulsivity (Douglas et al. 2003, 2004; Spear 2011; Casey and Caudle 2013; Galvan 2013). As a result, the prevalence of engaging in risk-

\footnotetext{
${ }^{2}$ Corresponding author

E-mail david.j.bucci@dartmouth.edu

Article is online at http://www.learnmem.org/cgi/doi/10.1101/lm.033787.113.
}

taking and injurious behavior (e.g., reckless driving and drug use) is higher in adolescents than in any other age group (Steinberg 2008). However, the nature of these impairments remains unclear since most prior work has focused on the expression or performance of inhibitory behavior by measuring, for example, premature responding or motor inhibition (Logan 1994; Robbins 2002; Eagle et al. 2008). In contrast, very few studies have considered how adolescents learn to inhibit a response.

To address this, Experiment 1 tested the ability of adolescent and adult rats to learn a Pavlovian negative occasion setting (NOS) task (Ross and Holland 1981; Holland 1984). In this procedure, rats received daily training sessions consisting of a subset of trials in which a tone (the "target" stimulus) was presented by itself and followed immediately by the delivery of food reward (the reinforcer, or unconditioned stimulus, US). On other trials, a light (the "feature" stimulus) was presented before the tone and no food was delivered. As shown previously, rats gradually learn to approach the food cup during presentation of the tone on trials when the light is not presented, and refrain from doing so on trials when the light is presented (Holland et al. 1999; MacLeod and Bucci 2010; MacLeod et al. 2010). In other words, rats learn to withhold responding to the target stimulus when the feature stimulus precedes it (Bouton and Nelson 1994; Holland and Morell 1996; Bueno and Holland 2008). In this way, the feature modulates the association between the target and the reinforcer, resulting in a learned inhibitory response that relies on encoding the meaning of the feature to correctly discriminate between trial types (Holland 1984). Indeed, one approach to negative occasion setting maintains that on reinforced trials an excitatory relationship is formed between the tone and the US, but on nonreinforced trials an inhibitory association between the tone and US

2014 Meyer and Bucci This article is distributed exclusively by Cold Spring Harbor Laboratory Press for the first 12 months after the full-issue publication date (see http://learnmem.cshlp.org/site/misc/terms.xhtml). After 12 months, it is available under a Creative Commons License (AttributionNonCommercial 3.0 Unported), as described at http://creativecommons. org/licenses/by-nc/3.0/. 


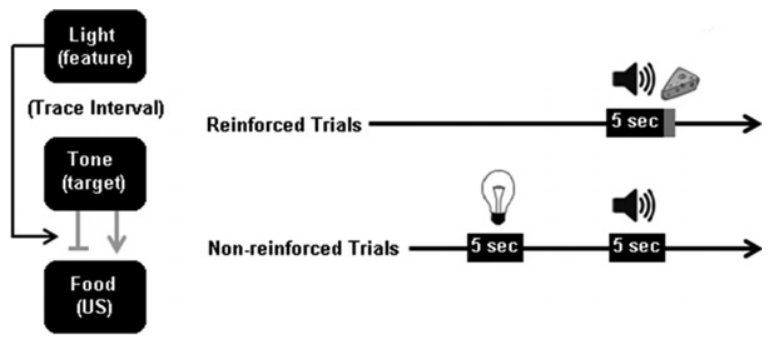

Figure 1. Schematic diagram of the negative occasion setting task. During reinforced trials, presentation of the tone was followed immediately by food reward. On nonreinforced trials, a light preceded the tone and no food was delivered.

is gated by the feature stimulus (Fig. 1; Bouton and Nelson 1994, 1998; Bouton 1997).

Prior studies have shown that negative occasion setting is impaired in adult rats following lesions of the prelimbic region of the medial prefrontal cortex (MacLeod and Bucci 2010), consistent with the widely held notion that inhibitory function depends on the prefrontal cortex (PFC) (Iversen and Mishkin 1970; Guitton et al. 1985; Diamond 1990; Sweeney et al. 1996; Cardinal et al. 2004). The purpose of Experiment 1 was to approach this from a new direction by comparing negative occasion setting in adult and adolescent rats. We predicted that, compared to adult rats, adolescents would exhibit a delay in learning to discriminate between reinforced and nonreinforced presentations of the tone since the PFC is not fully mature until late adolescence/early adulthood (Yakovlev 1962; Yakovlev and Lecours 1967; Orzhekhovskaya 1981; Sowell et al. 1999; Newman and McGaughy 2011). Experiment 2 addressed whether the differences in occasion setting observed between adolescent and adult rats in Experiment 1 resulted from an inability to learn the task rules or from a deficit in expressing that learning. Finally, in Experiment 3, we tested adult and adolescents in an alternate inhibitory learning paradigm to assess the generality of the findings from Experiment 1 and to address potential alternative explanations.

\section{Experiment 1}

\section{Results}

The amount of time spent in the food cup during presentation of the tone on reinforced and nonreinforced trials is shown in Figure 2. Consistent with our hypothesis, adult rats discriminated between reinforced and nonreinforced trials sooner (10 sessions, SEM $=3.65, P<0.001)$ than adolescents (18 sessions, $\mathrm{SEM}=$ 3.63, $P<0.001)$.

Time spent in the food cup during the 5 -sec period immediately after food was delivered was comparably high in both groups and did not differ significantly $\left(t_{(30)}=1.2, P>0.2\right)$. The means for the adult and adolescent rats were $4.3 \pm 0.2 \mathrm{sec}$ and $4.0 \pm 0.2 \mathrm{sec}$, respectively. Similarly, there were no group differences in food cup behavior during the 5 -sec period just prior to the onset of any stimuli (Pre-CS behavior, $t_{(30)}=0.6, P>0.6$ ). The mean amount of time spent in the food cup during the Pre-CS period was very low for both groups $(0.32 \pm 0.04 \mathrm{sec}$ and $0.35 \pm 0.04$ sec for adults and adolescents, respectively).

To address whether the discrimination was influenced by attention to the inhibitory cue, the time spent rearing during presentation of the light on nonreinforced trials was measured in both groups. As shown in Figure 3, the amount of time spent rearing to the light was very low in both adults and adolescents.
Nevertheless, an independent measures t-test revealed a marginally significant difference in that adult rats reared more than adolescents during presentation of the light $\left(t_{(30)}=2.0, P=\right.$ 0.06). Rearing during the $5 \mathrm{sec}$ prior to the presentation of any stimuli (Pre-CS period) was also very low and there was also a marginally significant difference between the groups $\left(t_{(30)}=2.0, P=\right.$ 0.06) (Fig. 3).

\section{Experiment 2}

In Experiment 1, adolescent rats required more sessions than adults to discriminate between reinforced and nonreinforced trials. One explanation for these results is that adolescent rats may have acquired the task rules (i.e., that the light indicated no reinforcement after the tone and that presentation of the tone alone was reinforced) in a similar number of sessions as adult rats, but were unable to express that learning until a certain age (i.e., about PND 50). To test this, three groups of rats were trained as illustrated in Figure 4. One set of rats (Paired group) began training in the negative occasion setting task on PND 35, receiving paired presentations of tone and food on some trials and nonreinforced pairings of the light and tone on other trials, exactly as in Experiment 1. Training was discontinued after six sessions and then resumed after a 9-d break. In this way, rats resumed training when they were 50 -d old, which is the age at which the adolescent group in Experiment 1 exhibited successful discrimination. We reasoned that if rats learned the meaning of the light and tone during the first six sessions, then they would
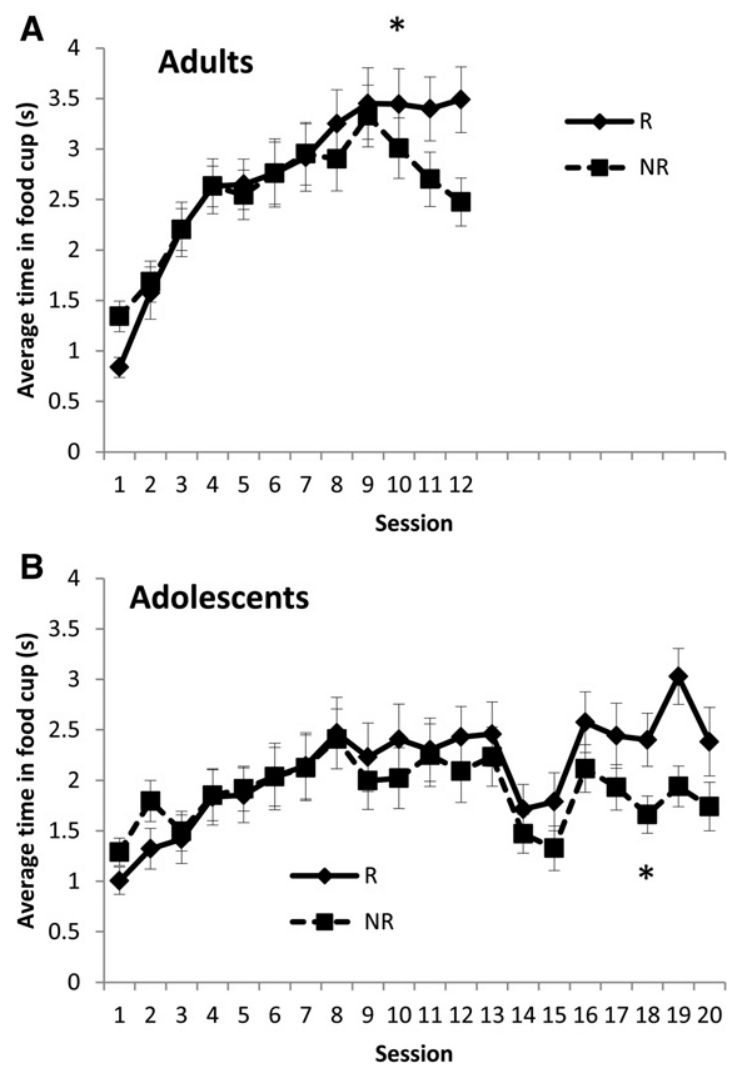

Figure 2. Food cup behavior during presentation of the tone on reinforced (R) and nonreinforced (NR) trials in adult $(A)$ and adolescent $(B)$ rats in Experiment 1. Adult rats learned to discriminate between trial types on session 10, while adolescent rats did not exhibit successful discrimination until session 18. $(*) P<0.01$. Data are means \pm SEM. 


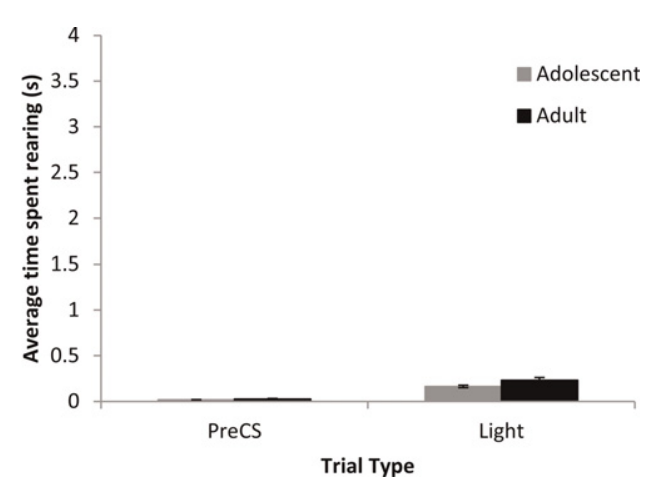

Figure 3. Orienting behavior (rearing) during presentation of the light and during the 5 -sec period before any stimuli were presented (Pre-CS) during nonreinforced trials. Adult rats tended to exhibit more rearing behavior during presentation of the light and during the Pre-CS period compared to adolescent rats $\left(P^{\prime} s=0.06\right)$. Data are means \pm SEM.

exhibit discrimination between the two trial types after fewer sessions when training resumed at PND 50 compared to rats that had no prior training and began negative occasion setting on PND 50 (No Pretraining group, Fig. 4). Specifically, we expected that the No Pretraining group would require approximately 10 sessions of training to exhibit successful discrimination, like the adult group in Experiment 1. The third group of rats in Experiment 2 began training on PND 35, but received unpaired presentations of the light, tone, and food during sessions 1-6 (Unpaired group). During each of these sessions, rats received 16 presentations of the tone alone, 12 presentations of the light alone, and four deliveries of food reward (randomly intermixed); thus, rats in the Unpaired group received the same total number of presentations of the stimuli as rats in the Paired group. After the 9-d break, they were trained in the standard negative occasion task like the Paired group and the No Pretraining group. Thus, the Unpaired group controlled for stimulus pre-exposure effects which could have influenced learning when the rats in the Paired group resumed training after the 9-d break. We predicted that rats in the Unpaired group, like those in the No Pretraining group, would require about 10 sessions of negative occasion setting training when it began on PND 50 to successfully learn the discrimination.

Alternatively, if the impairment observed in adolescent rats in Experiment 1 reflected an acquisition deficit, then we would expect that rats in the Paired group would not benefit from the first $6 \mathrm{~d}$ of training in the negative occasion setting task. Thus, after returning to the task after the 9-d break, rats in the Paired group should take as long as rats in the No Pretraining group (i.e., approximately 10 sessions) to successfully discriminate between reinforced and nonreinforced trials.

\section{Results}

As was the case in both the adolescent group and the adult group in Experiment 1 , rats in the Paired group exhibited increasing amounts of food cup behavior to the tone on both trial types during the first six sessions of training and did not discriminate between reinforced and nonreinforced trials (Fig. 5A). In addition, as was expected, rats in the Unpaired group exhibited very little conditioned food cup behavior during pres- entation of the light or the tone during the first six sessions (Fig. 5B) since the stimuli were not paired with food reward.

The primary data of interest were the learning curves for each of the three groups from PND 50 onward. The amount of time each group spent in the food cup during presentation of the tone on reinforced and nonreinforced trials is shown in Figure 6 (A-C). Rats in the Paired group began to discriminate significantly between the two trial types on session $5(\mathrm{SEM}=2.45, P<0.01)$. In contrast, the No Pretraining group and the Unpaired group each required 11 sessions until they exhibited significantly more food cup behavior to the tone on reinforced trials vs. nonreinforced trials $(\mathrm{SEM}=2.74, P<0.005$ and $\mathrm{SEM}=2.53, P<0.01$, respectively). Thus, when rats in all three groups received negative occasion setting training beginning on PND 50, rats in the Paired group needed six fewer sessions than rats in the other two groups to exhibit successful discrimination. This outcome is consistent with the interpretation that learning took place during the negative occasion setting sessions that occurred on PND 35-40 in rats in the Paired group. Moreover, in total, rats in the Paired group in Experiment 2 required seven fewer sessions to discriminate than rats in the adolescent group in Experiment 1, even though they both began training on PND 35. These findings indicate that the impairments observed in adolescent rats in Experiment 1 resulted from an expression deficit, rather than an acquisition deficit.

\section{Experiment 3}

Rather than being indicative of a deficit in inhibitory learning per se, the impairment observed in adolescent rats in Experiment 1 could have resulted from an inability to process information during the 5-sec interval between the light and the tone on nonreinforced trials (e.g., short-term memory). Indeed, prior studies have shown that juvenile rats exhibit deficits in trace conditioning compared to adult rats (Moye and Rudy 1987). This was tested in Experiment 3 by training an additional cohort of adult and adolescent rats in a procedure that was otherwise identical to the one used in Experiment 1, except that the light and the tone were presented simultaneously instead of serially on the nonreinforced trials. This procedure is commonly referred to as a "conditioned inhibition" paradigm and also involves learning to inhibit responding on nonreinforced trials, albeit through different behavioral mechanisms than the negative occasion setting paradigm (Bouton 2007). If the deficits in negative occasion setting in adolescent rats in Experiment 1 were due to an inability to process information during the light-tone interval, we predicted that adolescent and adult rats would exhibit comparable learning in the conditioned inhibition task. Alternatively, if the results of Experiment 1 were indicative of an inhibition deficit, we expected 

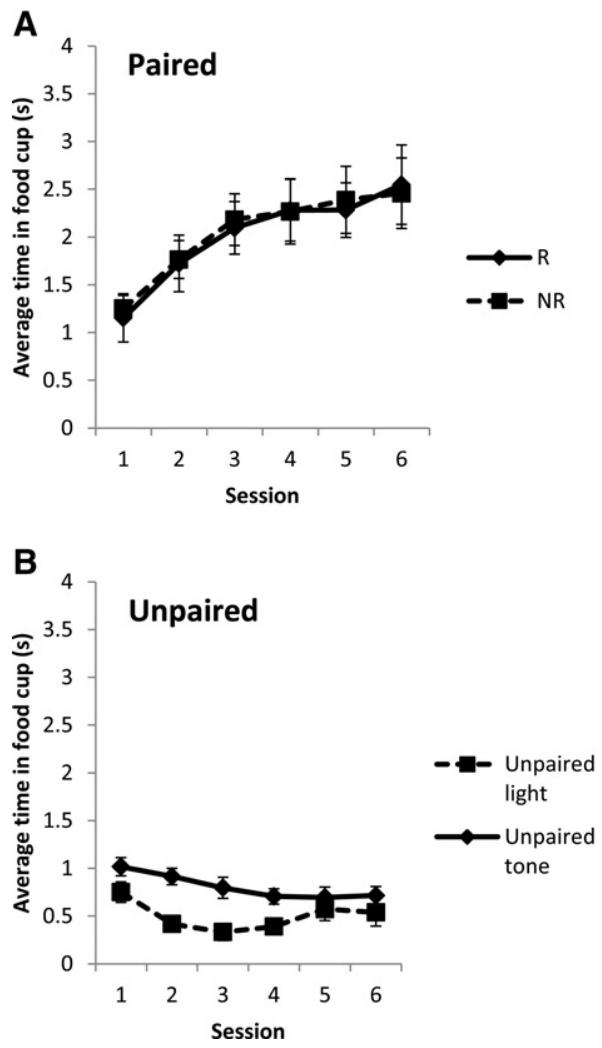

Figure 5. (A) Average time spent in the food cup during presentation of the tone on reinforced $(\mathrm{R})$ and nonreinforced (NR) trials during the first six training sessions beginning on PND 35 for the Paired group. The Paired group did not exhibit discrimination between reinforced and nonreinforced trials. (B) The Unpaired group exhibited low levels of responding during unpaired presentations of the light and tone during the first six sessions. Data are means \pm SEM.

that the impairment observed in adolescent rats would generalize to the conditioned inhibition procedure.

\section{Results}

The amount of time spent in the food cup during presentation of the tone on reinforced and nonreinforced trials in Experiment 3 is shown in Figure 7. Adult rats discriminated between reinforced and nonreinforced trials sooner (six sessions, $\mathrm{SEM}=4.87, P<$ 0.001 ) than adolescents (10 sessions, SEM $=2.63, P<0.005$ ).

\section{Discussion}

Experiment 1 tested the ability of adolescent and adult rats to learn to inhibit a behavioral response in a negative occasion setting paradigm. In the task used here, a tone was presented by itself and followed immediately by food reward, but no food was delivered when the tone was preceded by a light. Adult and adolescent rats began training on PND 70 and 35, respectively, and both groups learned to discriminate between the two trials types, as evidenced by significantly more food cup behavior when the tone was presented during reinforced trials compared to nonreinforced trials. However, adolescent rats required almost twice as many training sessions as adults to exhibit discrimination (i.e., rats in the adult group exhibited discrimination after 10 sessions while rats in the adolescent group did not discriminate until the 18th session).
Experiment 2 determined whether the impairment observed in adolescents in Experiment 1 reflected an acquisition deficit or an expression deficit. A group of rats that received six sessions of negative occasion setting training starting on PND 35 did not exhibit significant discrimination during those sessions, but when they were returned to the task after a 9-d break they needed only five more sessions of training to successfully inhibit responding to the tone on nonreinforced trials. In contrast, rats that instead received unpaired presentations of the light and tone during the first six sessions required 11 negative occasion setting sessions after the 9-d break to exhibit discrimination. Similarly, rats that had no prior training experience and began negative occasion setting training at $50 \mathrm{~d}$ of age also required 11 training sessions before they exhibited successful discrimination. Together, these data indicate that adolescent rats that started negative occasion setting training on PND 35 were able to learn (acquire) the dual meaning of the tone during the initial sessions, but could not express that learning until they reached $\sim 50 \mathrm{~d}$ of age.

An alternative explanation for the rapid discrimination exhibited by the Paired group in Experiment 2 when training resumed after the 9-day break is that simple pre-exposure to the
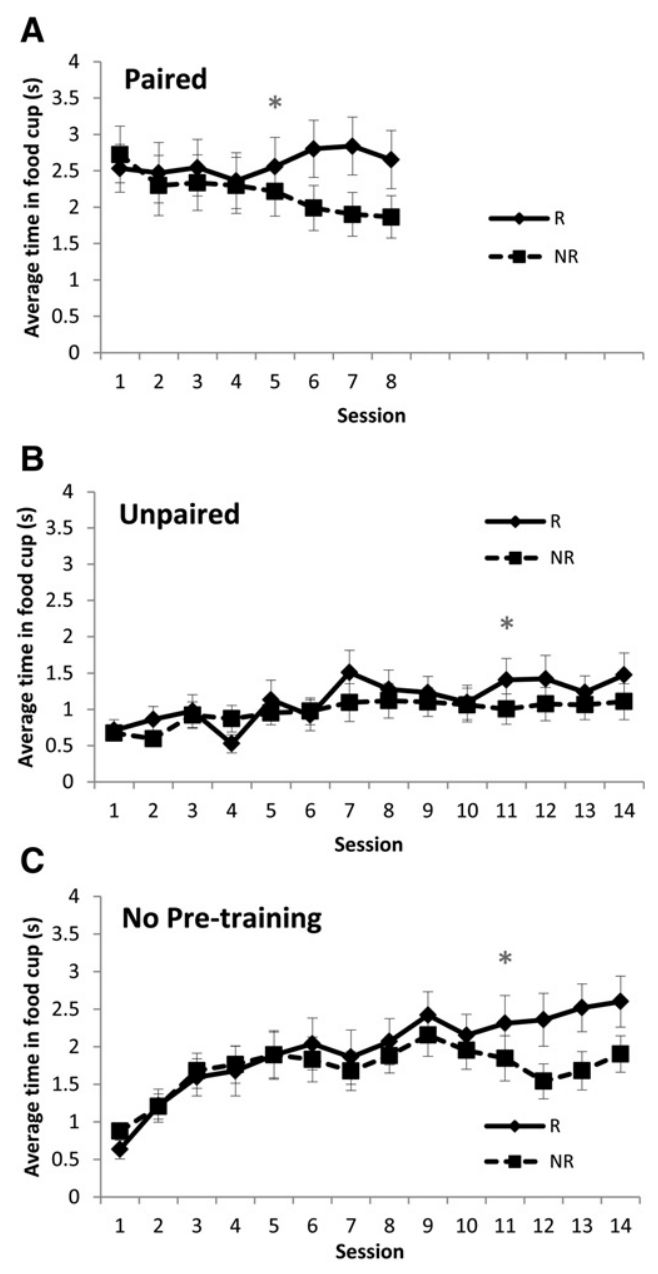

Figure 6. Average time spent in the food cup during presentation of the tone on reinforced (R) and nonreinforced (NR) trials for the three groups in Experiment 2 during NOS sessions beginning on PND 50. Rats in the Paired group $(A)$ learned to discriminate between trial types beginning on session 5, while rats in the Unpaired group $(B)$ and the group with No Pretraining $(C)$ did not successfully discriminate until session $11 .\left(^{*}\right)$ $P<0.01$. Data are means \pm SEM. 

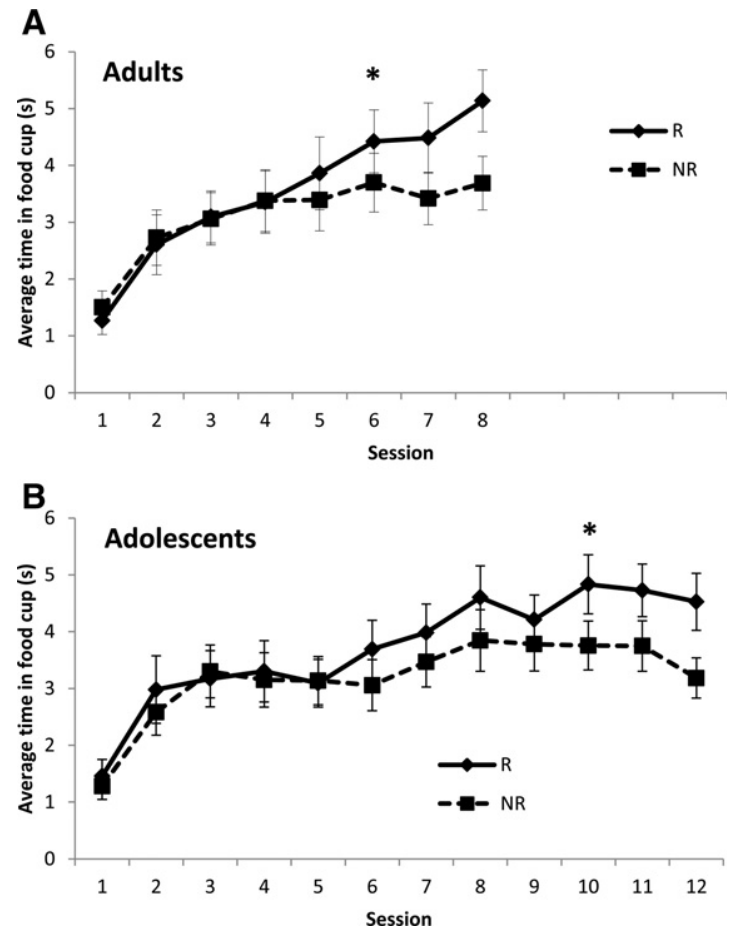

Figure 7. Food cup behavior during presentation of the tone on reinforced $(\mathrm{R})$ and the light-tone simultaneous-compound stimulus on nonreinforced (NR) trials in adult $(A)$ and adolescent $(B)$ rats in Experiment 3. Adult rats learned to discriminate between trial types on session 6 , while adolescent rats did not exhibit successful discrimination until session 10. $\left(^{*}\right) P<0.01$. Data are means \pm SEM.

stimuli during the first six training sessions aided subsequent learning about the stimulus contingencies. Indeed, prior studies have shown that stimulus pre-exposure can sometimes facilitate subsequent learning in young animals (Hoffmann and Spear 1989; Hendrix et al. 1993; Stanton et al. 1998). However, the performance of the Unpaired group in Experiment 2 suggests that this was not the case. Instead, as is more typically observed, stimulus pre-exposure reduced the overall level of responding to the food cup, indicative of latent inhibition (Rescorla 1967; Mackintosh 1974). These data indicate that stimulus pre-exposure cannot explain the rapid discrimination in the Paired group; rather, it was the explicit pairing of stimuli during the first six sessions that led to the savings observed in the Paired group. These findings provide additional evidence for an expression-based interpretation of the impairment in adolescents in Experiment 1.

Finally, Experiment 3 tested the ability of adult and adolescent rats to discriminate between reinforced and nonreinforced trials in a variant of the task in which the light and tone were presented simultaneously, rather than serially. Both groups learned to discriminate between the two trials types as evidenced by significantly more food cup behavior during the tone on reinforced trials compared to the light-tone simultaneous compound stimulus on nonreinforced trials. However, consistent with Experiment 1 , adolescent rats required more training sessions to exhibit successful discrimination. The adolescents required 10 sessions to respond significantly more on the reinforced trials versus the nonreinforced trials whereas adults learned the discrimination in only six sessions. These data indicate that the impairment in negative occasion setting observed in adolescent rats (Experiment 1) was not merely due to an inability to process information during the light-tone interval (i.e., a short-term memory deficit). Indeed, adolescent rats were impaired even when the light and tone were presented simultaneously (Experiment 3). Importantly, the results of Experiment 3 also reveal that the deficit in learning to inhibit responding in adolescence extends beyond the specific form of inhibition present in negative occasion setting.

Collectively, these findings are consistent with literature indicating that adult-like performance on tasks involving behavioral regulation and inhibition is not apparent until late adolescence or early adulthood in both humans and laboratory animals (Lin et al. 2000; Anderson et al. 2001; Romine and Reynolds 2005; Newman and McGaughy 2011). For example, adolescents exhibit perseveration in tasks involving rule changes, or shifts in attention to a new stimulus feature (Chelune and Baer 1986; Levin et al. 1991; Welsh et al. 1991; Riccio et al. 1994; Lin et al. 2000). Further, the difficulty in inhibiting inappropriate or irrelevant behaviors continues until PND 50 in the rat (Newman and McGaughy 2011). Importantly, the present data add to this literature by indicating that impairments in inhibitory behavior during adolescence do not reflect an inability to learn to inhibit a response, but instead reflect a specific deficit in expressing that learning. Similarly, it has been shown previously that the ability to learn to emit a behavioral response can precede the ability to overtly express the corresponding behavior (Bell and Livesey 1985; Marler 1990; Livesey and Morgan 1991; Stanton et al. 1998; Dowsett and Livesey 2000; Pattwell et al. 2011). For example, adolescent mice are capable of learning a contextual fear response as early as PND 23 and can translate that learning into a freezing response upon reaching adulthood. In contrast, expression of the learned fear response is temporarily suppressed during adolescence, implying that although the fear response can be acquired, it is not expressed during this period (Pattwell et al. 2011). Our results suggest that, in the same fashion, learning to omit a behavioral response can precede the ability to express that learning.

One explanation for the impairments observed in adolescence in our study is that the ability to withhold behavior is dependent on the maturation of the PFC. Consistent with this, the PFC has been shown to have an essential role in suppressing dominant response tendencies in favor of more appropriate goal-directed behaviors (Iversen and Mishkin 1970; Neill 1976; Guitton et al 1985; Diamond 1990; Sweeney et al. 1996; Fuster 1997; Roberts et al. 1998; Cardinal et al. 2004; Casey et al. 2005; Andrzejewski et al. 2011). Furthermore, PFC lesions produce deficits in negative occasion setting (MacLeod and Bucci 2010) and in conditioned inhibition (Meyer and Bucci 2013) in adult rats that are similar to the ones observed here in intact adolescent rats. The involvement of PFC in the deficits observed in negative occasion setting and conditioned inhibition in adolescence is also consistent with evidence that this region is one of the last brain areas to fully develop, undergoing prominent reorganization in adolescence and not reaching maturity until young adulthood (Huttenlocher 1979; St. James-Roberts 1979; Huttenlocher and de Courten 1987; Stuss 1992; Giedd et al. 1999; Casey 2000; Diamond 2002; Wishaw and Kolb 2004; Romine and Reynolds 2005; Crews et al. 2007). The PFC exhibits differential activation in children and adults in numerous tasks addressing behavioral inhibition (Casey et al. 1997b; Rubia et al. 2000; Bunge et al. 2002; Tamm et al. 2002; Crone et al. 2008), with both increased (Gravan et al. 1999; Tamm et al. 2002) and decreased (Casey et al. 1997a; Marsh et al. 2006) activations observed in children and adolescents compared to adults. Regulation of inappropriate thoughts and actions increases with age (Passler et al. 1985; Harnishfeger and Bjorklund 1993; Carver et al. 2001; Casey et al. 2002, 2005; Galvan et al. 2007; Yurgelun-Todd 2007), and the attainment of consistent inhibitory behavior has been linked 
to maturation of the PFC (Neill 1976; Cardinal et al. 2004; Andrzejewski et al. 2011).

The neural circuitry through which PFC might regulate behavioral responding in negative occasion setting or conditioned inhibition awaits further research, but existing data suggest that it may be mediated via frontal-striatal systems. Throughout childhood and adolescence, relevant projections from the PFC to the basal ganglia are enhanced while irrelevant projections are eliminated, as evidenced by synapse elimination and myelination (Kinney et al. 1988; Casey et al. 1997a, 2002; Giedd et al. 1999; Klingberg et al. 1999; Sowell et al. 1999; Rubia et al. 2000; Durston et al. 2002; Liston et al. 2006). Additionally, this maturation has been proposed to increase cognitive control and the inhibition of competing actions to guide relevant and appropriate behaviors (Mink 1996; Casey et al. 2002). In support of this theory, development of frontostriatal white matter tracts has been correlated with impulse control in a Go/No-Go task (Liston et al. 2005). These findings suggest that the behavioral impairments observed in adolescents may reflect less efficient neural activation compared to adults during the same task. Indeed, maturation and refinement of the projections to/from the PFC and striatum increases efficiency of behavioral regulation (Casey et al. 1997a; Tamm et al. 2002).

Distinguishing between acquisition and expression deficits during adolescence is essential for understanding the normal ontogeny of inhibitory function as well as the basis for inhibition deficits observed in neurodevelopmental cognitive disorders. Indeed, individuals with ADHD (Trommer et al. 1991; Barkley 1997; Casey et al. 1997a) or schizophrenia (Braff 1993; Asarnow et al. 1995) have difficulty regulating and suppressing inappropriate thoughts and actions. Furthermore, these disorders, as well as drug addiction, involve deficits in cognitive control and have been shown to involve the PFC (Lou et al. 1989; Castellanos et al. 1994, 1996; Fraizier et al. 1996; Casey et al. 2002; Cardinal et al. 2004; Feil et al. 2010; Goldstein et al. 2011). An interesting hypothesis is that dysregulation of the developmental events leading to functional maturation of the PFC may contribute to or trigger the onset of ADHD and schizophrenia (Woo and Crowell 2005). The negative occasion setting task used here may be particularly useful in testing these and other hypotheses. Indeed, although other tasks can be used to study the ability of rats to withhold a behavior response when signaled by a cue in the environment, such as the stop-signal reaction time task (Oosterlaan et al. 1998; Feola et al. 2000; Rubia et al. 2000; Eagle and Robbins 2003; Eagle et al. 2008), they often require extensive training periods that cannot be completed during the relatively brief period of adolescence (PND 28-45; Spear 2000). In contrast, rats are able to learn the negative occasion setting task within 2 wk, well within the timeframe of even the most conservative definitions of adolescence. In addition, negative occasion setting has particular relevance for understanding the role of contextual cues in regulating the emission or omission of behavioral responses (e.g., extinction) (Bouton 1997), which has direct implications for drug seeking and addiction-related behavior (Bouton et al. 1990; Conklin and Tiffany 2002; Janak et al. 2012), both of which are prevalent during adolescence.

A potential pitfall of using appetitive conditioning procedures with adolescent rats is that the procedures require food restriction, which could affect normal physiological and anatomical development (Andrzejewski et al. 2011). For example, Sturman et al. (2010) observed impaired operant extinction in adolescents compared to adults; however, further exploration showed these deficits existed only under conditions of food restriction. The authors concluded that motivational factors were largely responsible for the age-related differences, rather than impulsivity or behavioral inhibition. Thus, an alternative explana- tion for the findings in Experiment 1 is that adolescents and adults differed because of motivational factors. However, several features of the experimental design and data obtained in the present study argue against a motivational explanation.

First, we used a food-restriction protocol that was specifically designed to address this issue. Specifically, both adolescent and adult rats were allowed to gain weight each day. In contrast, in most other appetitive conditioning studies with adults, target weights are adjusted only weekly or monthly. Thus, the finding that adults still learn the task sooner than adolescents under these more conservative food-restriction conditions makes it less likely that results were caused by malnutrition in the adolescent group or motivational differences between the groups. Second, we found that adult and adolescent rats spent comparable amounts of time in the food cup after food was delivered and that both groups consumed all food pellets delivered in each session. Moreover, food cup behavior prior to stimulus onset was equivalent in both groups, indicating that there was no group difference in the motivational significance of the cup itself. Nonetheless, we did observe that excitatory conditioning (i.e., food cup entry on tone-alone trials) reached an asymptote of $\sim 3.5 \mathrm{sec}$ for rats in the fully adult group in Experiment 1, whereas the adolescents in Experiment 1 reached an asymptote of $\sim 2.5 \mathrm{sec}$. Thus, a difference in excitatory conditioning itself (due to a motivation difference) could have led to the delay in withholding responding observed in adolescences. However, comparing the performance of the adolescent and adult groups in Experiment 1 with the young adult (No-Pretraining group) in Experiment 2 provides further evidence against a motivational explanation. Indeed, although the young-adult group in Experiment 3 also achieved an asymptote of only $\sim 2.5 \mathrm{sec}$, that group was still able to withhold responding on nonreinforced trials and exhibit successful discrimination in only 10-11 sessions, like the fully adult group in Experiment 1 . This finding suggests that differences in excitatory conditioning due to motivational differences cannot explain the impairment observed in the adolescent rats in Experiment 1. Finally, it is important to note that an impairment in withholding responding was apparent in the conditioned inhibition procedure used in Experiment 3, despite there being equivalent levels of excitatory conditioning between adolescent and adult rats.

To determine whether the results of Experiment 1 were influenced by a group difference in attention to the inhibitory cue, the amount of time spent rearing during presentation of the light on nonreinforced trials was measured in adults and adolescents. The rearing response has often been used as a measure of attentional processing of visual stimuli (Kaye and Pearce 1984; Gallagher et al. 1990; Lang et al. 1997; Robinson et al. 2012). Thus, adolescents may have paid less attention to the light, an effect that might explain their inability to withhold responding during presentation of the tone on the nonreinforced trials. Although there was a trend for a statistically significant difference, the amount of time spent rearing to the light was extremely low in both adults and adolescences and they differed by $<0.1 \mathrm{sec}$. This likely reflected a technical limitation in that rearing by the smaller-sized adolescent rats was less likely to be detected by the elevated photobeam. Regardless, it seems unlikely that this small difference in time spent rearing to the light could account for the finding that adolescent rats required eight more training sessions than adults to successfully discriminate between reinforced and nonreinforced trials. Moreover, rats in the Paired group (Experiment 2) were able to discriminate between the trial types shortly after training resumed, indicating that they were indeed able to learn to inhibit responding during the first six sessions in that experiment despite potential differences in rearing to the light.

In summary, the experiments here demonstrate that adolescent rats are impaired in the ability to withhold a behavioral 
response as measured during a negative occasion setting task and a conditioned inhibition task. Additionally, the acquisition and expression of inhibitory learning appear to be ontogenetically separate processes that jointly determine when a particular learned response will emerge during development. Having a model that can be used in adolescence and combined with neurobiological studies will be very useful. In addition, studying the mechanisms of brain development and behavior in humans is limited by ethical and practicality issues, highlighting the need for an animal model to further explore the relationship between brain development and behavior. These findings provide a valuable framework for examining the neural substrates underlying maturation of inhibitory behavior.

\section{Materials and Methods}

\section{Experiment 1}

\section{Subjects}

Naive male Long Evans rats were obtained from Harlan Laboratories (Indianapolis) at either $21(n=16)$ or $56(n=16)$ days of age. Rats were housed individually and allowed at least $7 \mathrm{~d}$ to acclimate to the colony room prior to beginning food restriction and behavioral testing. Food (2014 Teklad Global 14\% Protein Rodent Maintenance Diet, Harlan Laboratories) and water were available ad libitum during this acclimation period. During the week prior to behavioral training, rats were handled daily and body weight was gradually reduced to $85 \%$ of the daily weight of free-feeding age-matched control rats using growth charts generated from over 60 subjects (provided by the vendor). Food restriction was maintained for all groups until completion of behavioral training, with supplemental rat chow given to each rat after the daily session to maintain the target weight. The colony room was maintained on a 14:10-h light-dark cycle and monitored and cared for in compliance with the Association for Assessment and Accreditation of Laboratory Animal Care guidelines and the Dartmouth College Institutional Animal Care and Use Committee.

\section{Behavioral apparatus}

Behavioral procedures were carried out in standard conditioning chambers (Med Associates). The chambers $(24 \times 30.5 \times 29 \mathrm{~cm})$ consisted of aluminum front and back walls, clear acrylic sides and top, and grid floors. Each chamber was outfitted with a dimly illuminated food cup, recessed in the center of the front wall, a 2.8 -W white panel light located $5 \mathrm{~cm}$ above the opening to the food cup, and a speaker located $15 \mathrm{~cm}$ above and to the right of the food cup, used to present the $1500-\mathrm{Hz}, 78-\mathrm{dB}$ auditory stimulus. Delivery of two 45-mg food pellets (Bioserv) served as the unconditioned stimulus. Each chamber was equipped with a pair of infrared photocells located across the entrance to the food cup to monitor entries into the cup and connected to a PC-clone computer. An additional pair of photobeam sensors was mounted in the chamber and used to detect rearing behavior. The sensors were placed $15 \mathrm{~cm}$ above the grid floor and just under the stimulus light. Each chamber was enclosed in a sound-attenuating cubicle $(62 \times 56 \times 56 \mathrm{~cm})$ with an exhaust fan to provide airflow and background noise $(\sim 68 \mathrm{~dB})$ and a red house-light (mounted on the ceiling) to provide background illumination. The cubicles also contained surveillance cameras used to monitor the rats during behavioral training.

\section{Behavioral procedure}

Each day, rats were placed in plastic transporters and moved from the colony room to the conditioning chambers. One day prior to behavioral training rats were trained to eat from the food cup during a single 64-min session in which two food pellets were randomly delivered 16 times (average intertrial interval (ITI) of 4 min, ranging from 2.5 to $5.5 \mathrm{~min}$ ). Behavioral training consisted of daily 64-minute sessions with four reinforced and 12 nonrein- forced trials (average ITI of $4 \mathrm{~min}$, ranging from 2.5 to $5.5 \mathrm{~min}$ ). During reinforced trials the tone was presented for $5 \mathrm{sec}$ and followed immediately by the delivery of two food pellets. On nonreinforced trials, the panel light was presented for 5 sec light, followed by a 5-sec empty period, and then a 5-sec presentation of the tone, after which no food was delivered. The two trial types occurred randomly during each session and the presentation order was varied daily. Rats in the adolescent group began training on PND 35 and rats in the adult group started training on PND 70. Training continued for up to $3 \mathrm{wk}$.

\section{Analysis of food cup behavior}

The primary variable of interest was the number of sessions that were required until rats exhibited successful discrimination between reinforced and nonreinforced presentations of the tone. To assess this, the amount of time that the photobeam in front of the food cup was broken during presentation of the tone was recorded during each trial. The amount of time spent in the food cup was averaged across rats in each group for each trial type. The difference in responding between trial types was obtained by subtracting the time spent in the food cup during the tone on nonreinforced trials from time spent in the food cup during the tone on reinforced trials. $Z$-scores were calculated by dividing that result by the SEM of the difference in responding across all rats in a group. Successful discrimination between the two trial types was defined as a greater amount of time spent in the food cup during presentation of the tone on reinforced trials than during nonreinforced trials (a $Z$-score of at least 2.325, $P<0.01$ ). Training was discontinued when this criterion was maintained for three consecutive days.

To test for possible differences in baseline responding or motivation, the amount of time spent with the head in the food cup was assessed during the 5-sec period immediately before any stimuli were presented (Pre-CS period), and immediately after food was delivered (Post-CS period), respectively. The mean Pre-CS and Post-CS food cup behavior was calculated across sessions and collapsed across the two trial types and subjected to an independent measures $t$-test.

\section{Analysis of orienting behavior}

During each presentation of the light on nonreinforced trials, the amount of time that the photobeam mounted on the walls of the chamber under the light was broken was monitored by a computer and used to measure orienting behavior. Orienting was defined as rearing on the hind legs with both forepaws off the ground (Holland 1977) and is often used as a measure of attentional processing (Kaye and Pearce 1984; Gallagher et al. 1990; Lang et al. 1997; Robinson et al. 2012). We also analyzed rearing behavior during the 5 sec prior to any stimulus presentation during nonreinforced trials (Pre-CS behavior). This was used to test for any group difference in baseline rearing behavior. Rearing behavior during presentation of the light on nonreinforced trials was averaged across sessions, and Pre-CS rearing behavior was averaged across sessions and collapsed across the two trials types; the resulting data were analyzed using independent samples $t$-tests. All analyses were carried out using SPSS and R statistical packages.

\section{Experiment 2}

\section{Subjects}

Forty-eight adolescent male Long Evans rats were obtained and housed as described for Experiment 1.

\section{Behavioral apparatus and procedure}

The conditioning chambers and general procedures were identical to those described in Experiment 1 with the following exceptions. Rats in the Paired group ( $n=16)$ received $6 \mathrm{~d}$ of negative occasion setting training starting on PND 35, followed by a 9-d break. Training then resumed when rats were 50 -d old. Rats in the 
Unpaired group $(n=16)$ likewise began training on PND 35 but were exposed to unpaired presentations of the light and tone. During a 68-min session, the light was presented by itself 12 times, the tone was presented by itself 16 times, and food was delivered four times. The stimuli were randomly presented during each session and the average intertrial interval was $\sim 2$ min. Finally, the No Pretraining group $(n=16)$ received negative occasion setting beginning on PND 50.

\section{Data analysis}

The data analysis procedures were identical to those described in Experiment 1 .

\section{Experiment 3}

\section{Subjects}

Sixteen adolescent and 16 adult male Long Evans rats were obtained and housed as described in Experiment 1.

\section{Behavioral apparatus, procedure, and data analysis}

The conditioning chambers and general procedures were identical with those described in Experiment 1 with the following exception: During nonreinforced trials, the light and tone were presented simultaneously for $10 \mathrm{sec}$. The data analysis procedures were identical to those described in Experiment 1.

\section{Acknowledgments}

We thank Dr. George Wolford for assistance with data analysis and Dr. Travis Todd for valuable comments on prior versions of the manuscript. The authors also acknowledge the contributions of Shanhu Hu and Rebecca Schneyer in generating pilot data leading to this study. This research was supported by NIH Grant R01DA027688 to D.J.B.

\section{References}

Anderson VA, Anderson P, Northam E, Jacobs R, Catroppa C. 2001. Development of executive functions through late childhood and adolescence in an Australian sample. Dev Neuropsychol 20: 385-406.

Andrzejewski ME, Schochet TL, Feit EC, Harris R, McKee BL, Kelley AE. 2011. A comparison of adult and adolescent rat behavior in operant learning, extinction, and behavioral inhibition paradigms. Behav Neurosci 125: 93-105.

Asarnow RF, Brown W, Strandburg R. 1995. Children with a schizophrenic disorder: Neurobehavioral studies. Eur Arch Psychiatry Clin Neurosci 245: 70-79.

Barkley RA. 1997. Behavioral inhibition, sustained attention, and executive functions: Constructing a unifying theory of ADHD. Psychol Bull 121: 65-94.

Bell JA, Livesey DJ. 1985. Cue significance and response regulation in 3- to 6-year-old children's learning of multiple choice discrimination tasks. Dev Psychobiol 18: 229-245.

Bouton ME. 1997. Signals for whether versus when an event will occur. In Learning, motivation, and cognition: The functional behaviorism of Robert C. Bolles (ed. Bouton ME, Fanselow MS), pp. 385-409. American Psychological Association, Washington, DC.

Bouton ME. 2007. Learning and behavior: A contemporary synthesis. Sinauer Associates, Inc., Sunderland, MA.

Bouton ME, Nelson JB. 1994. Context-specificity of target versus feature inhibition in a feature-negative discrimination. J Exp Psychol Anim Behav Process 20: $51-65$.

Bouton ME, Nelson JB. 1998. Mechanisms of feature-positive and feature-negative discrimination learning in an appetitive conditioning paradigm. In Occasion setting: Associative learning and cognition in animals (ed. Schmajuk N, Holland PC), pp. 69-112. American Psychological Association, Washington, DC.

Bouton ME, Kenney FA, Rosengard C. 1990. State-dependent fear extinction with two benzodiazepine tranquilizers. Behav Neurosci 104: $44-55$.

Braff DL. 1993. Information processing and attention dysfunctions in schizophrenia. Schizophr Bull 19: 233-259.

Bueno JL, Holland PC. 2008. Occasion setting in Pavlovian ambiguous target discriminations. Behav Processes 79: 132-147.
Bunge SA, Dudukovic NM, Thomason ME, Vaidya CJ, Gabrieli JDE, 2002 Immature frontal lobe contributions to cognitive control in children: Evidence from fMRI. Neuron 33: 301-311.

Cardinal RN, Winstanley CA, Robbins TW, Everitt BJ. 2004. Limbic corticostriatal systems and delayed reinforcement. Ann N Y Acad Sci 1021: $33-50$.

Carver AC, Livesey DJ, Charles M. 2001. Age related changes in inhibitory control as measured by stop signal task performance. Int J Neurosci 107: $43-61$.

Casey BJ. 2000. Disruption of inhibitory control in developmental disorders: A mechanistic model of implicated frontostriatal circuitry. In Mechanisms of cognitive development: The Carnegie symposium on cognition, (ed. Siegler RS, McClelland JL), Vol. 28, pp. 327-352. Erlbaum, Hillsdale, NJ.

Casey BJ, Caudle K. 2013. The teenage brain: Self control. Curr Dir Psychol Sci 22: 82-87.

Casey BJ, Castellanos FX, Giedd JN, Marsh WL, Hamburger SD, Schubert AB, Vauss YC, Vaituzis AC, Dickstein DP, Sarfatti SE, et al. 1997a. Implication of right frontostriatal circuitry in response inhibition and attention-deficit/hyperactivity disorder. J Am Acad Child Psychiatry 36: 374-383.

Casey BJ, Trainor RJ, Orendi JL, Schubert AB, Nystrom LE, Giedd JN, Castellanos FX, Haxby JV, Noll DC, Cohen JD, et al. 1997b. A developmental functional MRI study of prefrontal activation during performance of a go-no-go task. J Cogn Neurosci 9: 835-847.

Casey BJ, Tottenham N, Fossella J. 2002. Clinical, imaging, lesion and genetic approaches toward a model of cognitive control. Dev Psychobiol 40: $237-254$.

Casey BJ, Galvan A, Hare TA. 2005. Changes in cerebral functional organization during cognitive development. Curr Opin Neurobiol 15: $239-244$.

Casey BJ, Getz S, Galvan A. 2008. The adolescent brain. Dev Rev 28: $62-77$

Castellanos FX, Giedd JN, Eckburg P, Marsh WL, King AC, Hamburger SD Rapoport JL. 1994. Quantitative morphology of the caudate nucleus in attention-deficit hyperactivity disorder. Am J Psychiatry 151: $1791-1796$

Castellanos FX, Giedd JN, Marsh WL, Hamburger SD, Vaituzis AC, Dickstein DP, Sarfatti SE, Vauss YC, Snell JW, Lange N, et al. 1996. Quantitative brain magnetic resonance imaging in attention-deficit hyperactivity disorder. Arch Gen Psychiatry 53: 607-616.

Chelune GJ, Baer RA. 1986. Developmental norms for the Wisconsin Card Sorting test. J Clin Exp Neuropsychol 8: 219-228.

Conklin CA, Tiffany ST. 2002. Applying extinction research and theory to cue-exposure addiction treatments. Addiction 97: 155-167.

Crews F, He J, Hodge C. 2007. Adolescent cortical development: A critical period of vulnerability for addiction. Pharmacol Biochem Behav 86: 189-199.

Crone EA, Zanolie K, Van Leijenhorst L, Westenberg PM, Rombouts SA. 2008. Neural mechanisms supporting flexible performance adjustment during development. Cogn Affect Behav Neurosci 8: $165-177$.

Diamond A. 1990. The development and neural bases of memory functions as indexed by the A-not-B and delayed response tasks in human infants and infant monkeys. Ann N Y Acad Sci 608: 267-317.

Diamond A. 2002. Normal development of prefrontal cortex from birth to young adulthood: Cognitive functions, anatomy, and biochemistry. In Principles of frontal lobe function (ed. Stuss DT, Knight RT), pp. 466-503 Oxford University Press, London, UK.

Douglas LA, Varlinskaya EI, Spear LP. 2003. Novel-object place conditioning in adolescent and adult male and female rats: Effects of social isolation. Physiol Behav 80: 317-325.

Douglas LA, Varlinskaya EI, Spear LP. 2004. Rewarding properties of social interactions in adolescent and adult male and female rats: Impacts of social versus isolate housing of subjects and partners. Dev Psychobiol 45: $153-162$.

Dowsett SM, Livesey DJ. 2000. The development of inhibitory control in preschool children: Effects of "executive skills" training. Dev Psychobiol 36: $161-174$

Durston S, Thomas KM, Yang Y, Ulug AM, Zimmerman R, Casey BJ. 2002. A neural basis for development of inhibitory control. Dev Sci 5: $9-16$.

Eagle DM, Robbins TW. 2003. Inhibitory control in rats performing a stop-signal reaction-time task: Effects of lesions of the medial striatum and d-amphetamine. Behav Neurosci 117: 1302-1317.

Eagle DM, Baunez C, Hutcheson DM, Lehmann O, Shah AP, Robbins TW. 2008. Stop-signal reaction-time task performance: Role of prefrontal cortex and subthalamic nucleus. Cereb Cortex 18: 178-188.

Feil J, Sheppard D, Fitzgerald PB, Yücel M, Lubman DI, Bradshaw JL. 2010. Addiction, compulsive drug seeking, and the role of frontostriatal mechanisms in regulating inhibitory control. Neurosci Biobehav Rev 35: $248-275$. 
Feola TW, de Wit H, Richards JB. 2000. Effects of d-amphetamine and alcohol on a measure of behavioral inhibition in rats. Behav Neurosci 114: $838-848$.

Fraizier JA, Giedd JN, Hamburger SD, Albus KE, Kaysen D, Vaituzis AC, Rajapakse JC, Lenane MC, McKenna K, Jacobsen LK, et al. 1996. Brain magnetic resonance imaging in childhood-onset schizophrenia. Arch Gen Psychiatry 53: 617-624.

Fuster J. 1997. The prefrontal cortex: Anatomy, physiology, and neuropsychology of the frontal lobe, 3rd ed. Lippincott-Raven, New York.

Gallagher M, Graham PW, Holland PC. 1990. The amygdala central nucleus and appetitive pavlovian conditioning: Lesions impair one class of conditioned behavior. J Neurosci 10: 1906-1911.

Galvan A. 2013. The teenage brain: Sensitivity to rewards. Curr Dir Psychol Sci 22: 88-93.

Galvan A, Hare TA, Parra CE, Penn J, Voss H, Glover G, Casey BJ. 2006. Earlier development of the accumbens relative to orbitofrontal cortex might underlie risk-taking behavior in adolescents. J Neurosci 26: $6885-6892$.

Galvan A, Hare T, Voss H, Glover G, Casey BJ. 2007. Risk-taking and the adolescent brain: Who is at risk? Dev Sci 10: F8-F14.

Giedd JN, Blumenthal J, Jeffries NO, Castellanos FX, Liu H, Zijdenbos A, Paus T, Evans AC, Rapoport JL. 1999. Brain development during childhood and adolescence: A longitudinal MRI study. Nat Neurosci 2: 861-863.

Goldstein RZ, Moeller SJ, Volkow ND. 2011. Cognitive disruptions in drug addiction: A focus on the prefrontal cortex. In Neuroimaging in addiction (ed. Adinoff B, Stein EA), pp. 179-210. John Wiley \& Sons, Ltd, Chichester, UK.

Gravan H, Ross T, Stein E. 1999. Right hemispheric dominance of inhibitory control: An event related functional MRI study. Proc Am Philos Soc 96: 8301-8306.

Guitton D, Buchtel H, Douglas R. 1985. Frontal lobe lesions in man cause difficulties in suppressing reflexive glances and in generating goal-directed saccades. Exp Brain Res 58: 455-472.

Hare TA, Tottenham N, Galvan A, Voss HU, Glover GH, Casey BJ. 2008. Biological substrates of emotional reactivity and regulation in adolescence during an emotional go-nogo task. Biol Psychiatry 63: 927-934.

Harnishfeger KK, Bjorklund F. 1993. The ontogeny of inhibition mechanisms: A renewed approach to cognitive development. In Emerging themes in cognitive development, (ed. Howe ML, Pasnak R), Vol. 1 pp. 28-49. Springer-Verlag, New York.

Hendrix CS, Freeman JH, Stanton ME. 1993. Ontogeny of latent inhibition of eyeblink conditioning in the rat. Soc Neurosci Abstr 19: 1000.

Hoffmann H, Spear NE. 1989. Facilitation and impairment of conditioning in the preweanling rat after prior exposure to the conditioned stimulus. Anim Learn Behav 17: 63-69.

Holland PC. 1977. Conditioned stimulus as a determinant of the form of the Pavlovian conditioned response. J Exp Psychol Anim Behav Process 3: $77-104$.

Holland PC. 1984. Differential effects of reinforcement of an inhibitory feature after serial and simultaneous feature negative discrimination training. J Exp Psychol Anim Behav Process 10: 461-475.

Holland PC, Morell JR. 1996. The effects of intertrial and feature-target intervals on operant serial feature negative discrimination learning. Learn Motiv 27: 21-42.

Holland PC, Lamoureux JA, Han JS, Gallagher M. 1999. Hippocampal lesions interfere with Pavlovian negative occasion setting. Hippocampus 9: $143-157$.

Hunt P, Hess MF, Campbell BA. 1998. Inhibition of the expression of conditioned cardiac responses in the developing rat. Dev Psychobiol 33: $221-233$

Huttenlocher PR. 1979. Synaptic density in human frontal cortexdevelopmental changes and effects of aging. Brain Res 163: 195-205.

Huttenlocher PR, de Courten C. 1987. The development of synapses in striate cortex of man. Hum Neurobiol 6: 1-9.

Iversen SD, Mishkin M. 1970. Perseverative inference in monkeys following selective lesions of the inferior prefrontal convexity. Exp Brain Res 11: 376-386.

Ivkovich D, Paczkowski CM, Stanton ME. 2000. Ontogeny of delay versus trace eyeblink conditioning in the rat. Dev Psychobiol 36: 148-160.

Janak PH, Bowers MS, Corbit LH. 2012. Compound stimulus presentation and the norepinephrine reuptake inhibitor atomoxetine enhance longterm extinction of cocaine-seeking behavior. Neuropsychopharmacology 37: $975-985$

Johnson MH. 1995. The inhibition of automatic saccades in early infancy. Dev Psychobiol 28: 281-291.

Kaye H, Pearce JM. 1984. The strength of the orienting response during Pavlovian conditioning. J Exp Psychol Anim Behav Process 10: 90-109.

Kinney HC, Brody BA, Kloman AS, Gilles FH. 1988. Sequence of central nervous system myelination in human infancy. J Neuropathol Exp Neurol 47: $217-234$
Klingberg T, Vaidya CJ, Gabrieli JD, Moseley ME, Hedehus M. 1999. Myelination and organization of the frontal white matter in children: A diffusion tensor MRI study. Neuroreport 10: 2817-2821.

Lang PJ, Simons RF, Balaban MT. 1997. Attention and orienting: Sensory and motivational processes. Erlbaum, Hillsdale, NJ.

Levin HS, Culhane KA, Hartmenn J, Evankovich K, Mattson AJ, Harward H, Ringholz G, Ewing-Cobbs L, Fletcher JM. 1991. Developmental changes in performance on tests of purported frontal lobe functioning. Dev Neuropsychol 7: 377-395.

Lin CC, Chen WJ, Yang H-J, Hsiao CK, Tien AY. 2000. Performance on the Wisconsin Card Sorting Test among adolescents in Taiwan: Norms, factorial structure and relation to schizotypy. J Clin Exp Neuropsychol 22: 69-79.

Liston C, Watts R, Tottenham N, Davidson MC, Niogi S, Ulug AM, Casey BJ. 2006. Frontostriatal microstructure modulates efficient recruitment of cognitive control. Cereb Cortex 16: 553-560.

Livesey DJ, Morgan GA. 1991. The development of response inhibition in 4- and 5-year-old children. Aust J Psychol 43: 133-137.

Logan G. 1994. On the ability to inhibit thought and action. In Inhibitory processes in attention, memory and language (ed. Dagenbach D, Carr TH), pp. 189-239. Academic Press, San Diego, CA.

Lou HC, Henricksen L, Bruhn P, Borner H, Nielsen JB. 1989. Striatal dysfunction in attention deficit and hyperkinetic disorder. Arch Neurol 46: $48-52$.

Mackintosh N. 1974. The psychology of animal learning. Academic Press, London, UK

MacLeod J, Bucci DJ. 2010. Contributions of the subregions of the medial prefrontal cortex to negative occasion setting. Behav Neurosci 124: 321-328.

MacLeod J, Vucovich M, Bucci DJ. 2010. Differential effects of nicotinic acetylcholine receptor stimulation on negative occasion setting. Behav Neurosci 124: $656-661$.

Marler P. 1990. Song learning: The interface between behaviour and neuroethology. Philos Trans R Soc Lond B Biol Sci 329: 109-114.

Marsh R, Zhu H, Schultz R, Quackenbush G, Royal J, Skudlarski P, Peterson B. 2006. A developmental fMRI study of self-regulatory control. Hum Brain Mapp 27: 848-863.

Meyer HC, Bucci DJ. 2013. The neural substrates and development of learned inhibition. In 2013 Neuroscience meeting planner, abstract program no. 766.09. Society for Neuroscience, San Diego, CA.

Mink JW. 1996. The basal ganglia: Focused selection and inhibition of competing motor programs. Prog Neurobiol 50: 381-425.

Moye TB, Rudy JW. 1987. Ontogenesis of trace conditioning in young rats: Dissociation of associative and memory processes. Dev Psychobiol 20: $405-414$

Naneix F, Marchand AR, Di Scala G, Pape J-R, Coutureau E. 2012. Parallel maturation of goal-directed behavior and dopaminergic systems during adolescence. J Neurosci 32: 16223-16232.

Neill DB. 1976. Frontal-striatal control of behavioral inhibition in the rat. Brain Res 105: 89-103.

Newman L, McGaughy J. 2011. Adolescent rats show cognitive rigidity in a test of attentional set shifting. Dev Psychobiol 53: 391-401.

Oosterlaan J, Logan GD, Sergeant JA. 1998. Response inhibition in AD/HD, $\mathrm{CD}$, comorbid $\mathrm{AD} / \mathrm{HD}+\mathrm{CD}$, anxious, and control children: $\mathrm{A}$ meta-analysis of studies with the stop task. J Child Psychol Psychiatry 39: 411-425.

Orzhekhovskaya NS. 1981. Fronto-striatal relationships in primate ontogeny. Neurosci Behav Physiol 11: 379-385.

Passler MA, Isaac W, Hynd GW. 1985. Neuropsychological development of behavior attributed to frontal lobe functioning in children. Dev Neuropsychol 1: 349-370.

Pattwell SS, Bath KG, Casey BJ, Ninan I, Lee FS. 2011. Selective early-acquired fear memories undergo temporary suppression during adolescence. Proc Natl Acad Sci 108: 1182-1187.

Pattwell SS, Duhoux S, Hartley CA, Johnson DC, Jing D, Elliott MD, Ruberry EJ, Powers A, Mehta N, Yang RR, et al. 2012. Altered fear learning across development in both mouse and human. Proc Natl Acad Sci 109: $16318-16323$

Pattwell SS, Casey BJ, Lee FS. 2013. The teenage brain: Altered fear in humans and mice. Curr Dir Psychol Sci 22: 146-151.

Rescorla RA. 1967. Pavlovian conditioning and its proper control procedures. Psychol Rev 74: 71-80.

Riccio CA, Hall J, Morgan A, Hynd GW, Gonzalez JJ, Marshall RM. 1994. Executive function and the Wisconsin Card Sorting Test: Relationship with behavioral ratings and cognitive ability. Dev Neuropsychol 10: 215-229.

Robbins TW. 2002. The 5-choice serial reaction time task: Behavioural pharmacology and functional neurochemistry. Psychopharmacology 163: $362-380$.

Roberts AC, Robbins TW, Weiskrantz L. 1998. The prefrontal cortex. Oxford University Press, New York. 
Robinson A, Eggleston R, Bucci DJ. 2012. Physical exercise and catecholamine reuptake inhibitors affect orienting behavior and social interaction in a rat model of attention-deficit/hyperactivity disorder. Behav Neurosci 126: 762-771.

Romine CB, Reynolds CR. 2005. A model of the development of frontal lobe functioning: Findings from a meta-analysis. Appl Neuropsychol 12: $190-201$.

Ross RT, Holland PC. 1981. Conditioning of simultaneous and serial feature-positive discriminations. Anim Learn Behav 9: 293-303.

Rubia K, Overmeyer S, Taylor E, Brammer M, Williams SC, Simmons A, Andrew C, Bullmore ET. 2000. Functional frontalisation with age: Mapping neurodevelopmental trajectories with fMRI. Neurosci Biobehav Rev 24: $13-19$.

Rudy J, Morledge P. 1994. Ontogeny of contextual fear conditioning in rats: Implications for consolidation, infantile amnesia, and hippocampal system function. Behav Neurosci 108: 227-234.

Somerville LH. 2013. The teenage brain: Sensitivity to social evaluation. Curr Dir Psychol Sci 22: 121-127.

Somerville LH, Hare T, Casey BJ. 2011. Frontostriatal maturation predicts cognitive control failure to appetitive cues in adolescents. J Cogn Neurosci 23: 2123-2134.

Sowell ER, Thompson PM, Holmes CJ, Jernigan TL, Toga AW. 1999. In vivo evidence for post-adolescent brain maturation in frontal and striatal regions. Nat Neurosci 2: 859-861.

Spear LP. 2000. The adolescent brain and age-related behavioral manifestations. Neurosci Biobehav Rev 24: 417-463.

Spear LR. 2011. Adolescent neurobehavioral characteristics, alcohol sensitivities and intake: Setting the stage for alcohol use disorder? Child Dev Perspect 5: 661-667.

St. James-Roberts I. 1979. Neurological plasticity, recovery from brain insult, and child development. Adv Child Dev Behav 14: 253-319.

Stanton ME, Freeman JH Jr, Skelton RW. 1992. Eyeblink conditioning in the developing rat. Behav Neurosci 106: 657-665.

Stanton ME, Fox GD, Carter CS. 1998. Ontogeny of the conditioned eyeblink response in rats: Acquisition or expression? Neuropharmacology 37: $623-632$.

Steinberg L. 2008. A social neuroscience perspective on adolescent risk-taking. Dev Rev 28: 78-106.

Sturman DA, Moghaddam B. 2012. Striatum processes reward differently in adolescents versus adults. Proc Natl Acad Sci 109: 1719-1724.
Sturman DA, Mandell DR, Moghaddam B. 2010. Adolescents exhibit behavioral differences from adults during instrumental learning and extinction. Behav Neurosci 124: 16-25.

Stuss DT. 1992. Biological and psychological development of executive functions. Brain $\operatorname{Cog} n$ 20: $8-23$.

Sun HS, Cocker PJ, Zeeb FD, Winstanley CA. 2012. Chronic atomoxetine treatment during adolescence decreases impulsive choice, but not impulsive action, in adult rats and alters markers of synaptic plasticity gin the orbitofrontal cortex. Psychopharmacology 219: 285-301.

Sweeney JA, Mintun MA, Kwee S, Wiseman MB, Brown DL, Rosenberg DR, Carl JR. 1996. Positron emission tomography study of voluntary saccadic eye movements and spatial working memory. J Neurophysiol 75: $454-468$.

Tamm L, Menon V, Reiss AL. 2002. Maturation of brain function associated with response inhibition. J Am Acad Child Psychiatry 41: $1231-1238$.

Trommer BL, Hoeppner JA, Zecker SG. 1991. The go no-go test in attention deficit disorder is sensitive to methylphenidate. J Child Neurol 6: $128-131$.

Welsh MC, Pennington BF, Groisser DB. 1991. A normative-developmental study of executive function: A window on prefrontal function in children. Dev Neuropsychol 7: 131-149.

Wishaw I, Kolb B. 2004. The behavior of the laboratory rat: A handbook with tests. Oxford University Press, New York.

Woo T-U, Crowell A. 2005. Targeting synapses and myelin in the prevention of schizophrenia. Schizophr Res 73: 193-207.

Yakovlev PI. 1962. Morphological criteria of growth and maturation of the nervous system in man. Res Publ Assoc Res Nerv Ment Dis 39: $3-46$.

Yakovlev PI, Lecours AR. 1967. The myelogenetic cycles of regional maturation of the brain. In Regional development of the brain in early life (ed. Minkowski A), pp. 3-70. Blackwell Scientific, Oxford and Edinburgh, UK.

Yurgelun-Todd D. 2007. Emotional and cognitive changes during adolescence. Curr Opin Neurobiol 17: 251-257.

Received November 4, 2013; accepted in revised form December 9, 2013. 


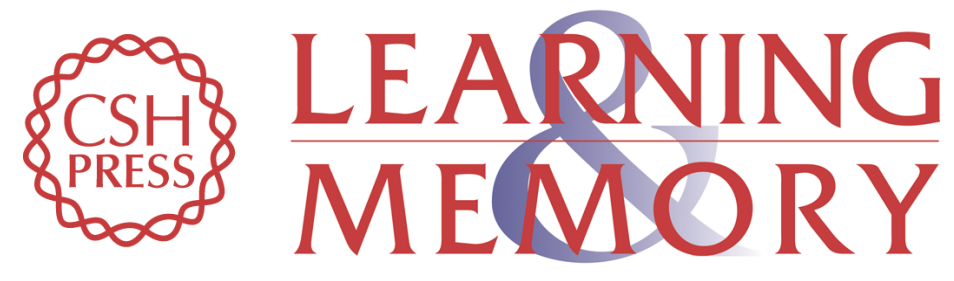

\section{The ontogeny of learned inhibition}

Heidi C. Meyer and David J. Bucci

Learn. Mem. 2014, 21:

Access the most recent version at doi:10.1101//m.033787.113

References This article cites 108 articles, 6 of which can be accessed free at: http://learnmem.cshlp.org/content/21/3/143.full.html\#ref-list-1

Creative This article is distributed exclusively by Cold Spring Harbor Laboratory Press for the Commons first 12 months after the full-issue publication date (see

License http://learnmem.cshlp.org/site/misc/terms.xhtml). After 12 months, it is available under a Creative Commons License (Attribution-NonCommercial 3.0 Unported), as described at http://creativecommons.org/licenses/by-nc/3.0/.

Email Alerting Receive free email alerts when new articles cite this article - sign up in the box at the Service top right corner of the article or click here. 